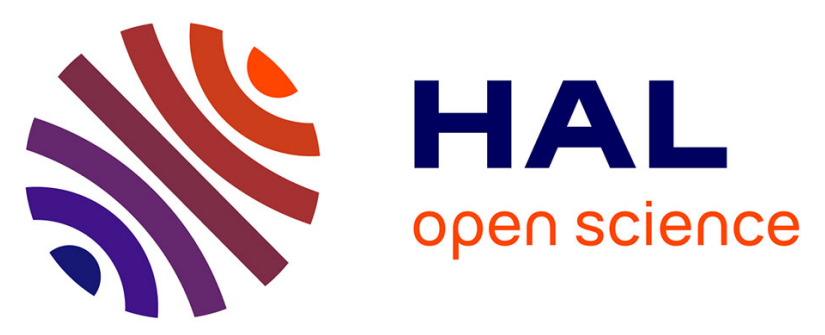

\title{
Electronic Decoupling in C3-Symmetrical Light-Responsive Tris(Azobenzene) Scaffolds: Self-Assembly and Multiphotochromism
}

Agostino Galanti, Valentin Diez-Cabanes, Jasmin Santoro, Michal Valášek, Andrea Minoia, Marcel Mayor, Jérôme Cornil, Paolo Samorì

\section{To cite this version:}

Agostino Galanti, Valentin Diez-Cabanes, Jasmin Santoro, Michal Valášek, Andrea Minoia, et al.. Electronic Decoupling in C3-Symmetrical Light-Responsive Tris(Azobenzene) Scaffolds: Self-Assembly and Multiphotochromism. Journal of the American Chemical Society, 2018, 140 (47), pp.16062-16070. 10.1021/jacs.8b06324 . hal-01986643

\section{HAL Id: hal-01986643 https://hal.science/hal-01986643}

Submitted on 28 Jan 2019

HAL is a multi-disciplinary open access archive for the deposit and dissemination of scientific research documents, whether they are published or not. The documents may come from teaching and research institutions in France or abroad, or from public or private research centers.
L'archive ouverte pluridisciplinaire HAL, est destinée au dépôt et à la diffusion de documents scientifiques de niveau recherche, publiés ou non, émanant des établissements d'enseignement et de recherche français ou étrangers, des laboratoires publics ou privés. 


\title{
Electronic Decoupling in $\mathrm{C}_{3}$-Symmetrical Light-Responsive Tris(Azobenzene) Scaffolds: Self-Assembly and Multi- Photochromism
}

\author{
Agostino Galanti, ${ }^{\dagger, \neq}$ Valentin Diez-Cabanes, ${ }^{\ddagger, \neq}$ Jasmin Santoro,§ Michal Valášek, ${ }^{\S,}{ }^{*}$ Andrea Minoia, ${ }^{\ddagger}$

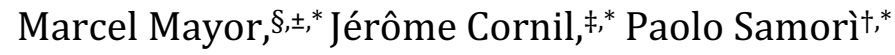

†Université de Strasbourg, CNRS, ISIS UMR 7006, 8 allée Gaspard Monge, 67000 Strasbourg, France

‡Laboratory for Chemistry of Novel Materials, University of Mons, Place du Parc 20, B-7000 Mons, Belgium

§Karlsruhe Institute of Technology KIT, Institute for Nanotechnology, P.O. Box 3640, 76021 Karlsruhe, Germany

„Department of Chemistry, University of Basel, St. Johannsring 19, 4056 Basel, Switzerland

KEYWORDS azobenzene $\bullet$ in-situ photoswitching • interfaces $\bullet$ scanning tunnelling microscopy • self-assembly

\begin{abstract}
We report the synthesis of a novel $\mathrm{C}_{3}$-symmetrical multiphotochromic molecule bearing three azobenzene units at positions 1,3,5 of the central phenyl ring. The unique geometrical design of such a rigid scaffold enables the electronic decoupling of the azobenzene moieties to guarantee their simultaneous isomerisation. Photoswitching of all azobenzenes in solution was demonstrated by means of UV-Vis absorption spectroscopy and high performance liquid chromatography (HPLC) analysis. Scanning tunnelling microscopy investigations at the solid-liquid interface, corroborated by molecular modelling, made it possible to unravel the dynamic self-assembly of such systems into ordered supramolecular architectures, by visualising and identifying the patterns resulting from three different isomers, thereby demonstrating that the multi-photochromism is retained when the molecules are confined in two-dimensions.
\end{abstract}

\section{INTRODUCTION}

Stimuli-responsive molecular systems have attracted a great interest because their physicochemical properties can be tuned when triggered by external chemical, electrochemical or optical inputs. ${ }^{1}$ Among them, light probably represents the most appealing way to enable complex function as a result of a stimulus because of its spatiotemporal resolution. ${ }^{2}$ Recently, with the aim to increase the functional complexity of molecular-scale events which can be attained with synthetic molecular systems, an increasing effort has been devoted to the integration of more than one photochromic unit into a single molecule to interconvert systems between multiple states in contrast to a simple photochromic molecule, which can be seen as a conventional binary switch. ${ }^{3}$

Among the various photochromic compounds, azobenzenes are of particular interest because of the large geometrical rearrangement occurring in the molecular backbone upon its $E-Z$ isomerisation, together with the dipole moment variation between the two isomers. Such a difference between the two forms can be used to execute mechanical work, ${ }^{4}$ and by extension to realise light-activated molecular actuators. ${ }^{5}$ With the implementation of such photoswitchable units into increasingly complex (supra)molecular systems, it was proven possible to optically gate various phenomena such as reversible supramolecular self-assembly, ${ }^{6}$ assembly of colloidal particles, ${ }^{7}$ current tunnelling within molecular junctions ${ }^{8}$ which led to the realisation of optically switchable electrical devices. ${ }^{9}$ Interestingly, by embedding azobenzene within crystalline or liquid crystalline matrices, it is possible to amplify its molecular-scale isomerisation into macroscopically observable effects such as photodeformation, ${ }^{10}$ light-controlled phase transition, ${ }^{11}$ and/or guest release. ${ }^{11 a},{ }^{12}$ While interrupting the electronic coupling in polyaromatic systems was seen to be essential in order to retain the photoresponsive properties in multi-azobenzene compounds, ${ }^{13}$ the use of an exemplary molecular design to cast light onto this aspect for a system containing up to three azobenzene units has never been reported.

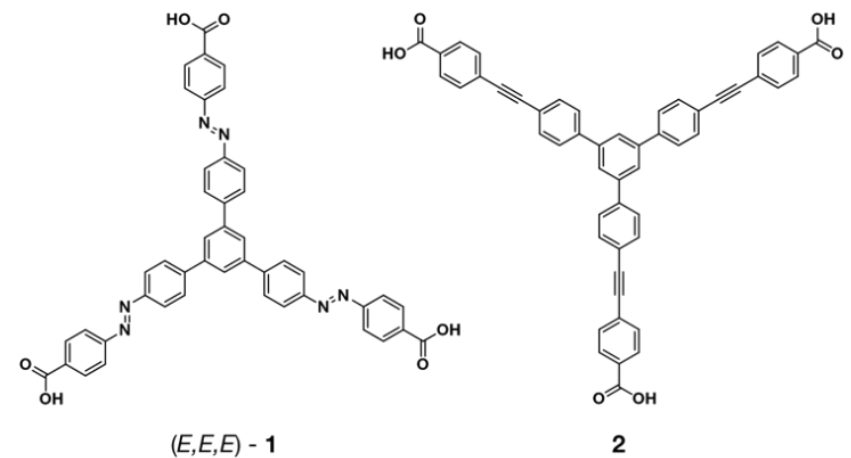

Figure 1. Chemical structure of tris(azobenzene) compound $\mathbf{1}$ and its non-photoactive analogue 2 . 


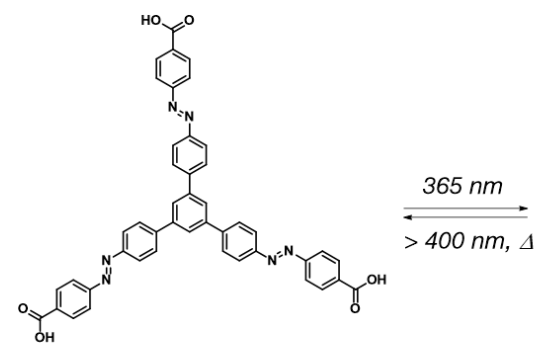

(E,E,E)-1

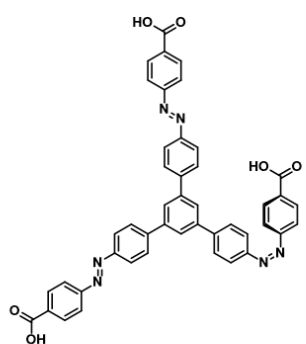

$(E, E, Z)-1$

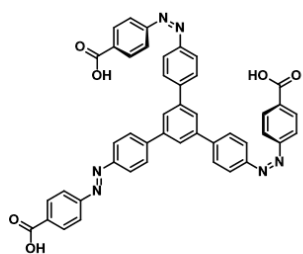

(E,Z,Z)-1

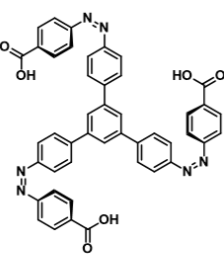

(Z,Z,Z)-1

Scheme 1. Isomerisation of tris(azobenzene) 1.

In the past two decades, scanning tunnelling microscopy (STM) has been widely employed as a powerful tool to study structure and dynamics of molecules at surfaces with a sub-nm resolution. ${ }^{14}$ In particular, STM imaging at the solid-liquid interface offers direct and detailed insight into the phenomenon of molecular self-assembly. ${ }^{15}$ Such a technique is increasingly employed for the study of hostguest, or stimuli responsive systems. ${ }^{16}$ Investigation on the isomerisation of azobenzene with STM has always been an appealing task for surface scientists, ${ }^{17}$ albeit the visualisation of the $Z$ isomer at the solid-liquid interface was found to be particularly challenging because of its non-planar, kinked geometry, which yields unfavourable van der Waals interactions with the underlying substrate surface. ${ }^{18}$ Therefore, the use of several artifices such as the decoration of the azobenzene with ad-hoc functional groups, or molecular geometries enabling the self-assembly of both $E$ and $Z$ isomers on graphite have demonstrated to be effective, although sometimes making their visualisation a cumbersome task. ${ }^{18-19}$ The STM mapping at the solid-liquid interface of various isomers of a photochromic system containing multiple azobenzene units in the same molecular backbone was achieved by embedding the switches in a host-guest network. ${ }^{20}$ Such a finding suggests that the isomerisation of multi-photochromic systems could be also monitored in mono-component ultrathin films by attaining an exquisite control over the interplay between intermolecular and interfacial interactions via an ad-hoc molecular design. In this regard, a rigid scaffold possessing a $C_{3}$ symmetry around a central benzene core appears ideal to address the key question of electronic decoupling on the isomerization of multiazobenzene systems and seems particularly suitable for the potential integration of such switches as building blocks for the generation of lightresponsive $2 \mathrm{D}$ and $3 \mathrm{D}$ metal-organic materials and covalent-organic frameworks. ${ }^{21}$

Here, we report on the design and synthesis of a novel $\mathrm{C}_{3}$-symmetrical multi-photochromic molecule $\mathbf{1}$ containing three azobenzene units branching out in the 1,3,5 positions of a central benzene ring. Optical characterisations by absorption spectroscopy combined with HPLC analysis have been performed in solution in order to explore the response of 1 to light at different wavelengths. STM investigation of the molecular self-assembly at the solid-liquid interface offered an in-depth insight into the responsive nature of the supramolecular assemblies of molecule $\mathbf{1}$ when in-situ irradiated with ultraviolet and visible light. The subtle interpretation of sub-molecularly resolved patterns was achieved with the aid of Molecular Mechanics/ Dynamics (MM/MD) simulations. In order to demonstrate that the dynamic self-assembly upon light irradiation at different wavelengths is due to the isomerisation of the three azobenzene moieties, we have extended our study to an analogue molecule $\mathbf{2}$ in which the diazene-1,2-diyl groups have been substituted with ethyn-1,2-diyl units, thus suppressing the photochromic nature of the system.

By design molecule $\mathbf{1}$ combines four structural features: (i) a noticeable conformational rigidity determined by the use of aromatic units, (ii) a central 1,3,5trisubstituted benzene ring-, which dictates the peculiar geometry of this molecule; (iii) the three azobenzene moieties which can respond to light stimuli; (iv) the carboxylic acid-terminated azobenzene arms to enable the use of intermolecular $\mathrm{H}$-bonding for controlling the self-assembly. The symmetry and peripheral functional groups of choice are motivated by the thorough investigation conducted in the past over the self-assembly of rigid aromatic carboxylic acids, ${ }^{22}$ especially $\mathrm{C}_{3}$-symmetric rigid tricarboxylic acids on HOPG (using heptanoic, octanoic or nonanoic acid as solvents) with increasingly large aromatic cores. $22 \mathrm{a}, 22 \mathrm{c}, 22 \mathrm{~d}, 22 \mathrm{f}$, $22 \mathrm{i}, 22 \mathrm{j}, 23$ Significantly, to cast light onto the role of the electronic coupling in polyaromatic systems containing multiple azobenzenes, we have devised a prototypical molecular design characterised by the reciprocal connection of the azobenzene moieties in the meta-position on the central phenyl ring to yield a partial interruption of the electronic communication between the photoactive units, yet keeping the system sufficiently rigid for allowing its self-assembly in 2D.

\section{RESULTS AND DISCUSSION}

To verify the occurrence of an efficient photochemical isomerisation of $\mathbf{1}, \mathrm{UV}$-Vis absorption spectroscopy and HPLC analysis were used (for synthesis and characterisation see SI). The absorption spectrum of $(E, E, E)-\mathbf{1}$ in DMSO shows the typical two bands of an azobenzene chromophore: $\pi-\pi^{*}$ and $n-\pi^{*}$ located respectively at ca. $370 \mathrm{~nm}$ and $455 \mathrm{~nm}$ (Figure 2).

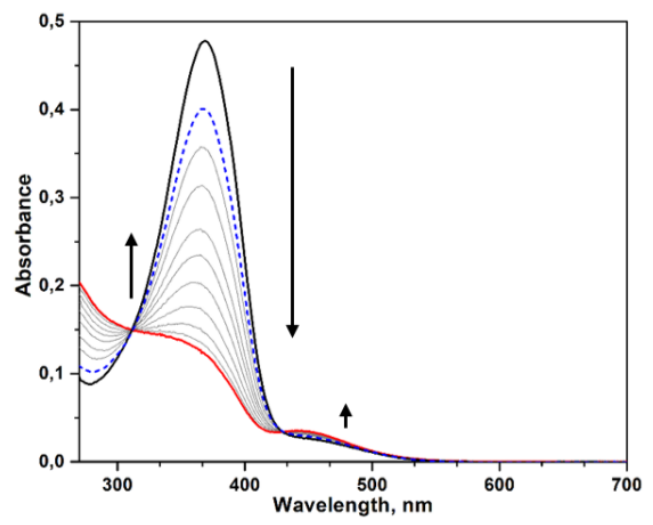


Figure 2. Absorption spectral variation of 1 upon UV $\left(\lambda_{\max }=\right.$ $365 \mathrm{~nm}$ ) irradiation in DMSO, c = 5.0×10-6 M. Full black line no irradiation, full red line PSS UV, dashed blue line, PSS Vis (irr. $\left.\lambda_{\max }=451 \mathrm{~nm}\right)$.

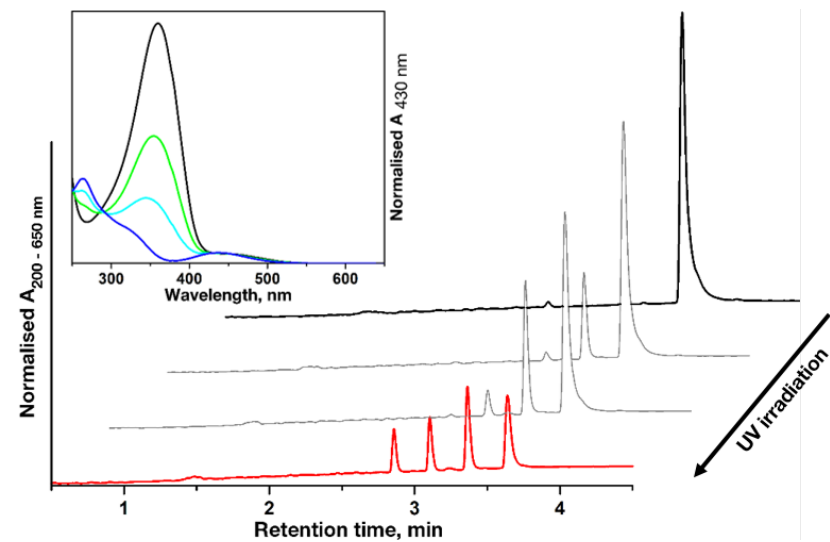

Figure 3. HPLC traces recorded upon injecting irradiated solutions of 1. Full black line no irradiation, full red line PSS UV. Inset, UV-Vis absorption spectra corresponding to the four peaks of PSS UV chromatogram. Black line, $(E, E, E)-\mathbf{1}$ (retention time: 3 min $38 \mathrm{~s}$ ), green line, $(E, E, Z)-1$ (retention time: 3 min $22 \mathrm{~s}$ ), light blue line, $(E, Z, Z)-1$ (retention time: 3 min $6 \mathrm{~s}$ ), blue line, $(Z, Z, Z)-1$ (retention time: 2 min $51 \mathrm{~s}$ ).

Upon UV irradiation at $365 \mathrm{~nm}$ of $\mathbf{1}$ in DMSO solution, a decrease in the strong $\pi-\pi^{*}$ transition was observed, together with an increase in absorption of the $n-\pi^{*}$ band. These features are typical for the $E \rightarrow Z$ isomerisation of azobenzene. Interestingly, the data exhibit sharp isosbestic points at ca. $312 \mathrm{~nm}$ and $430 \mathrm{~nm}$ which typically indicate electronic decoupling between azobenzene chromophores.13b Upon subsequent irradiation with visible light at ca. $450 \mathrm{~nm}$, a progressive recovery of the original spectral features was observed, while the full recovery to the initial scenario was achieved by storing the solution at room temperature in the dark over four days (or alternatively for ca. 12 hours at $50{ }^{\circ} \mathrm{C}$ ). The latter evidence confirms the full reversibility of the isomerisation of $\mathbf{1}$, i.e., a behaviour which is typical for azobenzene-based compounds. In order to clearly demonstrate the photochemical robustness of compound 1, we have performed a test over 10 photoswitching cycles, which showed negligible degradation of its photochromic activity (Figure S14). As previously seen, UV-Vis absorption spectroscopy does not allow to rationalise the isomeric composition of the mixture at the photo- stationary states (PSS), since all possible isomers of $\mathbf{1}$ absorb in the same spectral region. In principle, if all azobenzene units within 1 retain their photoreactivity, a mixture of the four possible $(E, E, E)-\mathbf{1},(E, E, Z)-\mathbf{1},(E, Z, Z)-\mathbf{1}$ and $(Z, Z, Z)-1$ isomers would be observed at the PSS. We used HPLC to separate the photogenerated isomers at the various steps of $\mathbf{1}$ photoisomerisation (Figure 3). The appearance of three additional peaks at lower elution time is observed upon UV irradiation. This is consistent with the generation of the expected photoproducts, possessing one, two and three azobenzene units in the $Z$ form. The absorption spectra recorded at the peaks of the chromatograms (Figure 3, inset) revealed that the spectra of the photoproducts display a progressive decrease of the $\pi-\pi^{*}$ band around $360 \mathrm{~nm}$ and an increase of the $n-\pi^{*}$ band with respect to $(E, E, E)-\mathbf{1}$, in consistency with the expected absorption spectra of the azobenzene $Z$ isomer. The insight offered by HPLC analysis is corroborated by the computed absorption spectra of the four possible isomers of $\mathbf{1}$ at the Time-Dependent Density Functional Theory (TD-DFT) level, which nicely correspond to those found experimentally (Figure S19). In agreement with the UV-Vis absorption spectroscopy, $Z \rightarrow E$ isomerisation of $\mathbf{1}$ with Vis light $\left(\lambda_{\max }\right.$ $=451 \mathrm{~nm}$ ) yields a PSS in which the population of the $Z$ isomers of $\mathbf{1}$ is partially converted to the $E$ ones, while the all-( $E$ ) situation is obtained by thermal $Z \rightarrow E$ isomerisation (Figure S13). Further photochemical characterisation about the composition of the photostationary state(s) and the role of conjugation in the present systems goes beyond the scope of this work.

Initially, we targeted at investigating the self-assembly of all- $(E)-1$ in the dark at the interface between its solution in 1-heptanoic acid (c = $10 \mu \mathrm{M})$ and highly ordered pyrolytic graphite (HOPG). Towards this end, to make sure that all three azobenzenes moieties of molecule $\mathbf{1}$ were in their all-(E) state, we applied to the surface a drop of a nonirradiated solution of $\mathbf{1}$, in order to benefit from the thermodynamic stability of $(E)$-azobenzene isomer. The STM images recorded in-situ display a tightly packed 2D crystalline lamellar structure consisting of $(E, E, E)-1$ arranged in a zig-zag fashion (Figure 4, Figure $5 a$ ). The structure observed displays a unit cell: $\mathrm{a}=4.1 \pm 0.2 \mathrm{~nm}, \mathrm{~b}=3.0 \pm 0.3$ $\mathrm{nm}, \alpha=41 \pm 5^{\circ}$ with an area $\mathrm{A}=8.7 \pm 0.3 \mathrm{~nm}^{2}$, each containing two molecules. A careful image analysis revealed the absence of polymorphs of such a crystalline packing, also upon varying the concentration of 1 solution used for the experiments: $10 \mu \mathrm{M}$ was found to be the optimal value

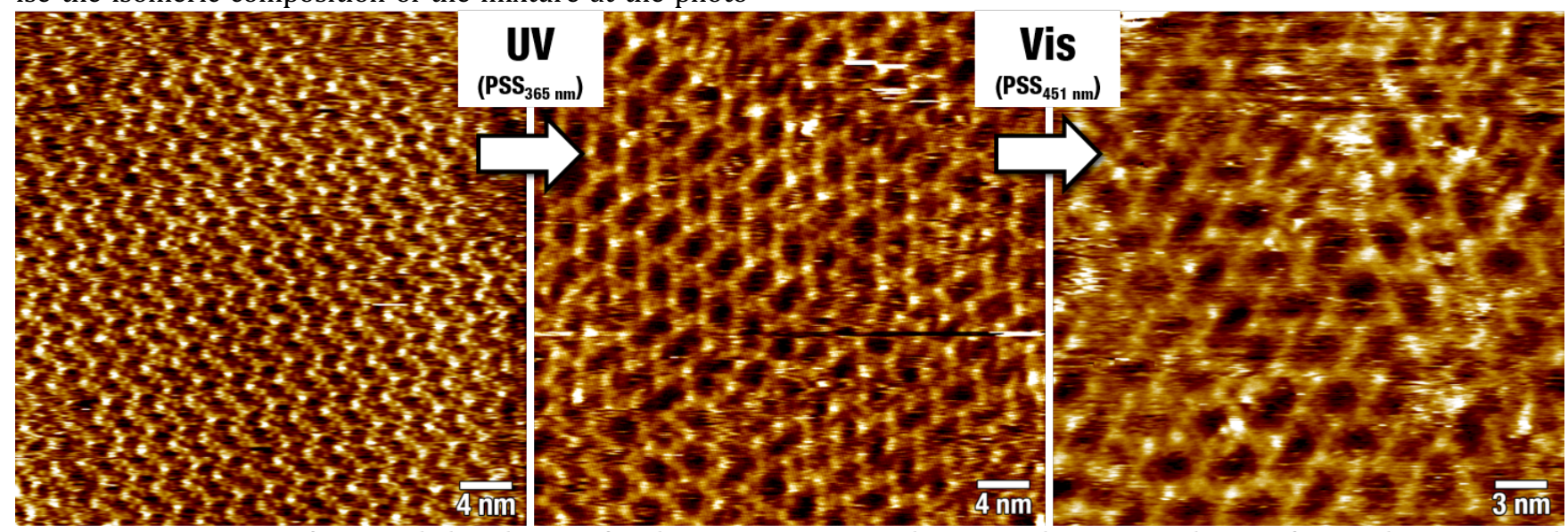

Figure 4. STM images of 1 recorded at the interface between an HOPG substrate and a $10 \mu \mathrm{M}$ solution of 1 in 1-heptanoic acid. Left, no light irradiation (average tunnelling current ( $\left.\mathrm{IT}_{\mathrm{T}}\right)=30 \mathrm{pA}$, tip bias voltage $\left.\left(\mathrm{V}_{\mathrm{T}}\right)=+800 \mathrm{mV}\right)$. Centre, in-situ UV $\left(\lambda_{\max }=365\right.$ $\mathrm{nm})$ light irradiation $\left(\mathrm{I}_{\mathrm{T}}=30 \mathrm{pA}, \mathrm{V}_{\mathrm{T}}=+800 \mathrm{mV}\right)$. Right, subsequent in-situ Vis $\left(\lambda_{\max }=451 \mathrm{~nm}\right)$ light irradiation $\left(\mathrm{I}_{\mathrm{T}}=20 \mathrm{pA}, \mathrm{V}_{\mathrm{T}}=\right.$ $+800 \mathrm{mV}$ ). 

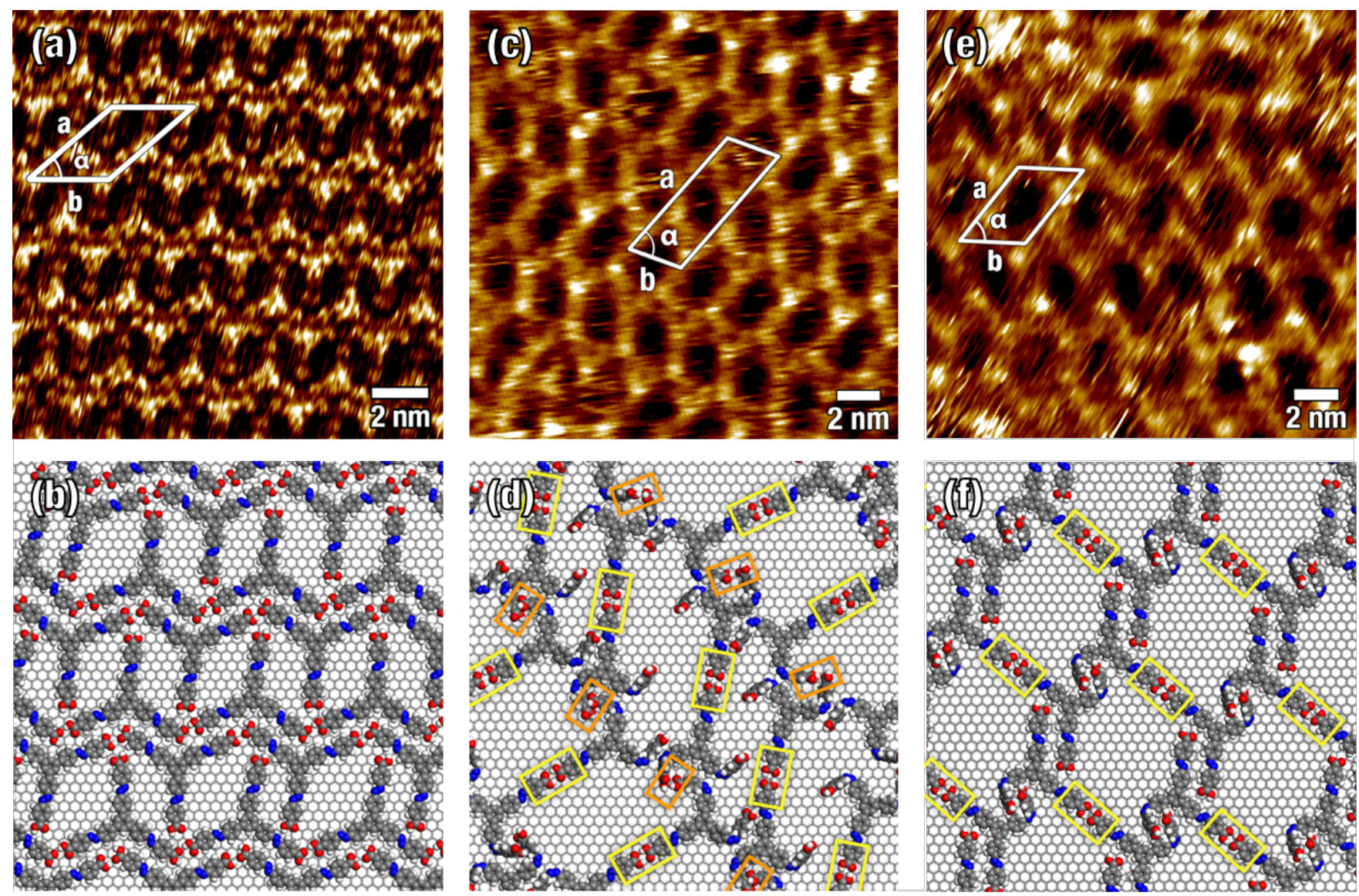

Figure 5. High resolution STM images of ordered domains of (a) $(E, E, E)-1$, (c) $(E, Z, Z)-1$, and (e) $(E, E, Z)-1$ self-assembled at the HOPG-solution interface using 1-heptanoic acid as solvent. Supramolecular packing models obtained by MM/MD simulations for (b) $(E, E, E)-\mathbf{1}$, (d) $(E, Z, Z)-\mathbf{1}$, and (f) $(E, E, Z)-\mathbf{1}$. The yellow rectangles indicate the formation of hydrogen bonded carboxylic acid dimers between $(E)$-azobenzene arms. Orange rectangles indicate hydrogen bonds between carboxylic moieties positioned on $(Z)$ azobenzene arms. Tunneling parameters: (a) average tunnelling current $\left(\mathrm{I}_{\mathrm{T}}\right)=40 \mathrm{pA}$, tip bias voltage $\left.\left(\mathrm{V}_{\mathrm{T}}\right)=+800 \mathrm{mV}\right),(\mathrm{c}) \mathrm{I}_{\mathrm{T}}=30$ $\mathrm{pA}, \mathrm{V}_{\mathrm{T}}=+800 \mathrm{mV}$, (e) $\mathrm{I}_{\mathrm{T}}=20 \mathrm{pA}, \mathrm{V}_{\mathrm{T}}=+800 \mathrm{mV}$.

for attaining higher spatial resolution (for details see SI). The total absence of the ideal "honeycomb network" Hbonded pattern which should arise from the formation of the intermolecular 2 -fold cyclic $\mathrm{O}-\mathrm{H} \cdots \mathrm{O}$ bonding between carboxylic groups is not surprising. This consideration comes from the large dimension of the rigid aromatic core of $\mathbf{1}$, in line with the reported tendency of large $\mathrm{C}_{3}$ symmetric tricarboxylic acids to form more densely packed structures. ${ }^{23}$ The reason for this evidence was explained by the higher adsorption energy contribution obtained by forming a more densely packed crystal with a non-ideal H-bonding pattern compared to the corresponding "ideal" honeycomb structure expected from the generation of the two-fold H-bonding dimers, leading to a looser crystalline structure. In other words, the most prominent term driving the assembly is not associated to intermolecular interactions, but rather to the molecule-substrate adsorption energy per unit area, thus yielding the "tightest" assembly and not the "ideal" H-binding motif. ${ }^{23}$ In order to confirm the assignment of the molecular packing given by experimental data, we simulated the assembly of $(E, E, E)-1$ by Molecular Dynamics (MD, see SI for details), which yielded an average unit cell: $\mathrm{a}=4.3 \mathrm{~nm}, \mathrm{~b}=2.8 \mathrm{~nm}, \alpha$ $=41^{\circ}$, with two molecules per unit cell (Figure $5 \mathrm{~b}$ ). The result obtained by MD simulations matches very well the experimental values obtained by STM, therefore confirm- ing the validity of our model. The azobenzene units in molecule 1 present a kink in the CNNC bond, it thus follows that upon the adsorption of $\mathbf{1}$ on the HOPG surface the resulting structures could show two isomers of the compound, together with the possibility of the emergence of their chirality. Nevertheless, from the images obtained, we could not attain the level of detail needed to neither assign unambiguously which specific isomer the crystalline domains belonged to, nor to comment about the chirality of the $2 \mathrm{D}$ structures.

As a blank experiment, the same study was also performed on the non-photochromic compound 2, displaying a similar geometry to $(E, E, E)-\mathbf{1}$, but having tolane moieties instead of azobenzenes in each of the three "arms". The experiment was performed after confirming the absence of photoreactivity of $\mathbf{2}$ by UV-Vis absorption spectroscopy (Figure S15). Compound $\mathbf{2}$ was found to self-assemble in a crystalline structure with the same symmetry displayed by $(E, E, E)-1$ (Figure S17). Such structure is characterised by the following unit cell: $\mathrm{a}=4.2 \pm 0.2 \mathrm{~nm}, \mathrm{~b}=2.9 \pm 0.1 \mathrm{~nm}, \alpha$ $=46 \pm 1^{\circ}$ with an area $\mathrm{A}=8.8 \pm 0.4 \mathrm{~nm}^{2}$, each containing two molecules. The parameters are substantially unvaried when compared with $(E, E, E)-\mathbf{1}$, within experimental error. A blank test performed by irradiating 2 solutions in-situ 
with both UV and visible light did not lead to any perceivable variation in the supramolecular packing (Figure S18).

Interestingly, the in-situ photoirradiation of a solution of $(E, E, E)-\mathbf{1}$ with ultraviolet light is generally accompanied with a loss of ordered crystalline packing, indicating a decrease in concentration of the $(E, E, E)-\mathbf{1}$ isomer. The general disappearance of the initial packing was seen logical knowing the lower stability of the azobenzene $Z$-isomer when adsorbed on a surface, due to its non-planar geometry. ${ }^{18}$ Surprisingly, in such a situation it was also possible to visualise domains of $\mathbf{1}$ displaying a periodical assembly (Figure 4). From our interpretation, each domain is composed by one isomer: $(E, Z, Z)-\mathbf{1}$ and $(E, E, Z) \mathbf{- 1}$.

For $(E, Z, Z)-\mathbf{1}$, the estimated unit cell parameters are the following: $\mathrm{a}=7.6 \mathrm{~nm}, \mathrm{~b}=2.7 \mathrm{~nm}, \alpha=69^{\circ}$ with an area $\mathrm{A}=20 \mathrm{~nm}^{2}$, each containing four molecules (Figure $5 \mathrm{c}$ ). Conversely, for $(E, E, Z)-\mathbf{1}$ we estimate the following unit cell: $\mathrm{a}=4.0 \mathrm{~nm}, \mathrm{~b}=3.3 \mathrm{~nm}, \alpha=55^{\circ}$ with an area $\mathrm{A}=11$ $\mathrm{nm}^{2}$, each containing two molecules (Figure 5e). Both assemblies display notably different geometry and unit cell parameters compared to $(E, E, E)-\mathbf{1}$ and 2. Moreover, their stability appears lower compared to the one of the $(E, E, E)$ $\mathbf{1}$, being evidenced by the smaller size of the ordered domains, and the sometimes fuzzy contrast visible in the STM images. Interestingly it was not possible to visualise the formation of ordered domains formed by $(Z, Z, Z)-\mathbf{1}$; this observation can be ascribed to the non-planar conformation of the three $(Z)$-azobenzene units, lowering the energy of adsorption of the molecules on the basal plane of graphite and hence providing unfavourable geometry for stabilisation via H-bonding with neighbouring molecules. Upon subsequent visible light irradiation, a radical change in the supramolecular assembly was evidenced, yielding a scenario in which the only ordered domains monitored at the interface were those containing $(E, E, Z)-\mathbf{1}$ (as mentioned above, Figure 4, Figure 5e).

Moreover, it is striking to observe how the ordered domains of both the photoproducts $(E, Z, Z)-\mathbf{1}$ and $(E, E, Z)-\mathbf{1}$ show a less dense crystalline packing compared to $(E, E, E)$ 1 and $\mathbf{2}$ (Figure 5, Table 1) which is in line with the larger stability in the STM imaging of the monolayers of the $(E, E, E)-1$. One explanation for this observation could come from the non-planar conformation of the $Z$-isomer of the azobenzene units, resulting in less favourable moleculesubstrate interactions compared to the $E$ form. This lower stabilisation is balanced by the formation of stronger intermolecular hydrogen bonds, such as carboxylic acid dimers, as evidenced by the larger spacing between rows of $(E, Z, Z) \mathbf{- 1}$ and $(E, E, Z) \mathbf{- 1}$, compared to $(E, E, E)-\mathbf{1}$. The formation of intermolecular carboxylic acid dimers between two $(E)$-azobenzene branches in the crystalline domains of $(E, Z, Z) \mathbf{- 1}$ and $(E, E, Z) \mathbf{- 1}$ is nicely supported by MM/MD simulations (see details in SI). For both $(E, Z, Z)-\mathbf{1}$ and $(E, E, Z)-\mathbf{1}$, the complicated H-bonding pattern forced us to perform the simulation over multiple different possible assemblies, in order to interpret correctly the experimental data (Table 1, Figure S22). In this context, it is important to mention that the majority of the starting geometries used to model $(E, Z, Z)-\mathbf{1}$ and $(E, E, Z)-\mathbf{1}$ ended up in amorphous structures after the MM/MD run. Only a few of them presenting motion constrained by additional H-bonds showed a clear assembly pattern. In all cases, the H-bonding between two carboxylic groups takes place (yellow rectangles in Figure 5d, f, Figure S22), thus confirming its crucial role for the stabilisation of the supramolecular packing. In some models, surprisingly, it was necessary to consider also the occurrence of hydrogen bonds between carboxylic moieties positioned on $(Z)$-azobenzene arms in order to obtain a stable structure (orange rectangles in Figure $5 d$, Figure $\mathrm{S} 22 \mathrm{~b}, \mathrm{c})$. For $(E, Z, Z)-\mathbf{1}$, the structure reproducing best the experimental pattern consists of model II (Table 1, Figure S22), with the following parameters: $a=7.6 \mathrm{~nm}, \mathrm{~b}=$ $2.8 \mathrm{~nm}, \alpha=74^{\circ}$ with an area $\mathrm{A}=20 \mathrm{~nm}^{2}$, each containing four molecules. Regarding this isomer, it is important to point out that several types of assemblies were considered and analysed, but only the assemblies presenting H-bonds between $(Z)$-azobenzene arms were able to form stable ordered assemblies, thus confirming the importance of these bonds in the stability of the assembly. For $(E, E, Z)-\mathbf{1}$, the chosen model I yields an unit cell: $\mathrm{a}=3.8 \mathrm{~nm}, \mathrm{~b}=3.3$ $\mathrm{nm}, \alpha=56^{\circ}$ with an area $\mathrm{A}=11 \mathrm{~nm}^{2}$, each containing two molecules. In this case, the computed structures highlight the presence of $\pi-\pi$ interactions between two out-of-plane phenyl rings of adjacent $(E, E, Z)-\mathbf{1}$ molecules dominating over the formation of additional H-bonds (Figure 5f, Figure

Table 1. Experimental and modelled unit cell parameters for 1 and 2 , and estimated thermodynamic quantities

\begin{tabular}{|c|c|c|c|c|c|c|c|c|c|c|c|c|c|}
\hline & & & $\mathrm{a}[\mathrm{nm}]$ & & $\mathrm{b}[\mathrm{nm}]$ & & $\alpha\left[^{\circ}\right]$ & $\mathrm{A}\left[\mathrm{nm}^{2}\right]$ & & $\mathrm{Na}^{\mathrm{a}}$ & H-bonds ${ }^{b}$ & $\begin{array}{l}\mathrm{E}_{\mathrm{ads}} \\
{[\mathrm{kcal} / \mathrm{mol}]^{\mathrm{c}}}\end{array}$ & $\mathrm{BE}[\mathrm{kcal} / \mathrm{mol}]^{\mathrm{d}}$ \\
\hline \multirow[t]{2}{*}{$(E, E, E) \mathbf{- 1}$} & \multicolumn{2}{|c|}{ experimental } & $\begin{array}{l}(4.1 \\
0.2)\end{array}$ & \pm & $\begin{array}{l}(3.0 \\
0.3)\end{array}$ & \pm & $(41 \pm 5)$ & $\begin{array}{l}(8.7 \\
0.7)\end{array}$ & \pm & 2 & & & \\
\hline & \multicolumn{2}{|c|}{ theoretical } & 4.3 & & 2.8 & & 41 & 8.0 & & & 2 & -101.91 & -6.83 \\
\hline 2 & \multicolumn{2}{|c|}{ experimental } & $\begin{array}{l}(4.2 \\
0.2)\end{array}$ & \pm & $\begin{array}{l}(2.9 \\
0.1)\end{array}$ & \pm & $(46 \pm 1)$ & $\begin{array}{l}(8.8 \\
0.4)\end{array}$ & \pm & 2 & & & \\
\hline \multirow{3}{*}{$(E, Z, Z)-\mathbf{1}$} & \multirow{3}{*}{$\begin{array}{l}\text { theoret- } \\
\text { ical }\end{array}$} & I & 8.1 & & 3.7 & & 61 & 26 & & \multirow{3}{*}{4} & 1.5 & -80.50 & -6.63 \\
\hline & & II & 7.6 & & 2.8 & & 74 & 20 & & & 2 & -78.84 & -10.13 \\
\hline & & III & 7.8 & & 3.3 & & 56 & 21 & & & 2.5 & -78.59 & -8.63 \\
\hline$(E, E, Z) \mathbf{- 1}$ & \multicolumn{2}{|c|}{ experimental } & $(4.0)$ & & $(3.3)$ & & (55) & (11) & & 2 & & & \\
\hline
\end{tabular}

aNumber of molecules per unit cell, ${ }^{b}$ Number of $\mathrm{H}$-bonds with neighbouring molecules, cAdsorption energy, average interaction energy of an individual molecule adsorbed on graphite, dBinding energy, average interaction energy between neighbouring molecules 
S22b I).

To obtain a more complete interpretation of our experimental findings, we casted down the different energies driving the 2D self-assemblies of $(E, E, E)-\mathbf{1},(E, Z, Z)-\mathbf{1}$ and $(E, E, Z)-1$ on graphene. For this purpose, we have computed two parameters: adsorption energy (Eads) and binding energy (BE), giving us a hint on the strength of the molecule-substrate and intermolecular interactions, respectively (Table 1 and SI). From the data, it is clear that the structural packing of both $(E, Z, Z)-\mathbf{1}$ and $(E, E, Z)-\mathbf{1}$ gives rise to a lower $E_{\text {ads }}$ compared to $(E, E, E)-\mathbf{1}$, due to the lower $\pi-\pi$ interaction caused by the azobenzene units in the $(Z)$ conformation. This result rationalises the fact that no selfassembly for $(Z, Z, Z)-\mathbf{1}$ was observed at the experimental level. Conversely, for $(E, E, Z) \mathbf{- 1}$ and $(E, Z, Z) \mathbf{- 1}$ the larger $B E$ values are related to the formation of a strong $\mathrm{H}$-bonding network stabilising the supramolecular packing. The oppositive behaviour of $E_{\text {ads }}$ and $\mathrm{BE}$ when going from $(E, E, E)$ $\mathbf{1}$ to its isomers validates our interpretation of the experimental molecular patterns visualised by STM. By and large, the computational insights confirm that the self-assembly of such large aromatic carboxylic acids is driven by a complicate interplay between intermolecular- and molecule/substrate- interactions. For the planar all- $(E)-\mathbf{1}$ the geometry of the 2D crystalline assembly is governed by the thermodynamics of strong molecule/substrate interactions leading to a tightly packed unit cell. The photogenerated $(Z)$-isomers show less favourable molecule/substrate interactions due to their non-planar conformation; this is, however, compensated by more stable hydrogen bonding interactions between the carboxylic groups, and/or $\pi-\pi$ interactions between adjacent out-of-plane phenyl rings. The aforementioned intermolecular interactions allow the formation of stable supramolecular assemblies showing larger unit cells compared to all- $(E)-1$, which are particularly unusual in view of the known tendency of rigid carboxylic acids to form a dense crystal structure. ${ }^{23}$

In order to cast further light onto whether the isomerization takes place or not on the basal plane of the surface, we have extended our study to the STM visualization of the isomerisation occurring in dry films, i.e. at the solid-air interface, of $\mathbf{1}$ physisorbed on the HOPG surface upon in-situ irradiation (Figure S16, see SI for details). This was done by depositing molecule $\mathbf{1}$ from a non-irradiated solution in THF on graphite substrates by means of spin-coating. The high affinity of the large aromatic core of $\mathbf{1}$ for the basal plane of HOPG made it possible to obtain a molecular adsorbate characterised by small crystalline regions alternated by un-coated substrate regions, thus yielding a submonolayer coverage. From semi-quantitative point of view, the unit cell of $(E, E, E)-\mathbf{1}$ monitored by STM at the solidliquid and at the solid-air interface are similar. Interestingly, upon performing in-situ irradiation of the sample with ultraviolet light, we could observe an evident variation of the original pattern visualised prior to light irradiation (Figure S16) as a result of the molecular isomerisation. In such a condition, thus in the absence of a medium capable of solvating $\mathbf{1}$, the adsorbates cannot desorb from the graphite substrate. The striking variation of the inter-row spacing compared to the non-irradiated situation is the most evident consequence of the external stimulus given by UV light. It is however evident how the morphology of the patterns seen upon irradiation at the solid-liquid interface is different from what obtained in the latter experiments: in such a scenario, the molecules are not capable of desorbing from the surface upon isomerisation, thus to rearrange forming 2D crystalline domains, each formed by only one $Z$-isomer, as previously mentioned, and visible in Figure 5. In the photoswitching experiments performed on $\mathbf{1}$ at the graphite-air interface we could on the contrary observe the neighbouring molecules within the same row being most likely present in the same configuration, nevertheless the molecular configuration of the neighbouring rows seems to vary randomly in the ordered domains. Thus, failing to form regular crystalline domains containing one, single isomer (see Figure S16). In light of these experimental evidences, we believe that we can safely state that in the STM experiments performed at the solid-liquid interface, the change in the geometry of the supramolecular 2D assemblies is due to the competitive adsorption of $(E, Z, Z)-\mathbf{1}$ and $(E, E, Z) \mathbf{- 1}$ isomers, following the isomerisation of $(E, E, E)-1$ in solution. Even though we cannot neglect that the molecules can isomerise when adsorbed on the graphite surface, we envision that in such a case the result would be largely different.

\section{CONCLUSIONS}

In summary, a novel rigid multiphotochromic system $\mathbf{1}$ based on three azobenzene chromophores attached to the 1,3 and 5 positions of a central benzene ring has been designed and synthesised in order to explore the role of electronic decoupling in the isomerization of the individual azobenzene moieties. Photoswitching of all three azobenzene units embedded in the $\mathrm{C}_{3}$-symmetrical rigid molecular scaffold was qualitatively confirmed by UV-Vis absorption spectroscopy and liquid chromatography in solution. Each photochromic unit was found to retain its photoresponsive nature, thus yielding a reversible mixture of four different isomers upon photoirradiation of a solution of all- $(E)-\mathbf{1}$ with ultraviolet light. In-situ STM investigation on the selfassembly of $\mathbf{1}$ at the graphite-solution interface revealed the formation of patterns of all-(E)-1. Upon in-situ irradiation with ultraviolet and visible light we evidenced the variation of the supramolecular packing, resulting from the formation of crystalline assemblies of two different partially $(Z)$-isomers. For the first time, we were able to identify by STM the existence of multiple isomeric states of a multiphotochromic compound in single-component selfassembled networks with a high level of details. We believe that the present results could be of great value for further research on multiphotochromic systems, and could clarify the role of non-covalent interactions in the supramolecular self-assembly of similar systems. In view of the intrinsic molecular geometry and rigidity, we envision that our multi-azobenzene compound could be employed in the future as building blocks of photo-responsive materials for various applications such as light-triggered host-guest systems, or optically-responsive metal-organic frameworks.

\section{ASSOCIATED CONTENT}

The Supporting Information is available free of charge via the Internet at http://pubs.acs.org.. 
Detailed experimental procedures; synthesis and characterisation of the products, computational methodologies.

\section{AUTHOR INFORMATION}

\section{Corresponding Authors}

*samori@unistra.fr,*jerome.cornil@umons.ac.be,

*michal.valasek@kit.edu,*marcel.mayor@unibas.ch

\section{Author Contributions}

₹These authors contributed equally.

\section{ACKNOWLEDGEMENTS}

We gratefully thank Dr. Sara Bonacchi and Dr. Martin Herder for enlightening discussions. This work was supported by the EC through the Marie Sklodowska-Curie ITN project iSwitch (GA-642196), the Agence Nationale de la Recherche through the LabEx project Chemistry of Complex Systems (ANR-10LABX-0026_CSC) and the International Center for Frontier Research in Chemistry (icFRC). M.V. and M.M. acknowledge financial support by the Helmholtz Research Programm STN (Science and Technology of Nanosystems). Computational resources were provided by the Consortium des Équipements de Calcul Intensif (CÉCI) funded by the Belgian National Fund for Scientific Research (F.R.S.-FNRS) under Grant 2.5020.11. J.C. is an FNRS research director.

\section{REFERENCES}

(1) (a) Kinbara, K.; Aida, T. Toward Intelligent Molecular Machines: Directed Motions of Biological and Artificial Molecules and Assemblies. Chem. Rev. 2005, 105 (4), 1377-400; (b) Browne, W. R.; Feringa, B. L. Making molecular machines work. Nat. Nanotechnol. 2006, 1 (1), 25-35; (c) Balzani, V.; Credi, A.; Venturi, M. Light powered molecular machines. Chem. Soc. Rev. 2009, 38 (6), 1542-50; (d) Erbas-Cakmak, S.; Leigh, D. A.; McTernan, C. T.; Nussbaumer, A. L. Artificial Molecular Machines. Chem. Rev. 2015, 115 (18), 10081-206.

(2) (a) Saha, S.; Stoddart, J. F. Photo-Driven Molecular Devices. Chem. Soc. Rev. 2007, 36 (1), 77-92; (b) Russew, M. M.; Hecht, S. Photoswitches: from Molecules to Materials. Adv. Mater. 2010, 22 (31), 3348-60; (c) Szymański, W.; Beierle, J. M.; Kistemaker, H. A.; Velema, W. A.; Feringa, B. L. Reversible photocontrol of biological systems by the incorporation of molecular photoswitches. Chem. Rev. 2013, 113 (8), 6114-78.

(3) (a) Perrier, A.; Maurel, F.; Jacquemin, D. Single Molecule Multiphotochromism with Diarylethenes. Acc. Chem. Res. 2012, 45 (8), 1173-82; (b) Fihey, A.; Perrier, A.; Browne, W. R.; Jacquemin, D. Multiphotochromic Molecular Systems. Chem. Soc. Rev. 2015, 44 (11), 3719-59.

(4) Hugel, T.; Holland, N. B.; Cattani, A.; Moroder, L.; Seitz, M.; Gaub, H. E. Single-Molecule Optomechanical Cycle. Science 2002, 296 (5570), 1103-6.

(5) (a) Takashima, Y.; Hatanaka, S.; Otsubo, M.; Nakahata, M.; Kakuta, T.; Hashidzume, A.; Yamaguchi, H.; Harada, A. Expansion-contraction of photoresponsive artificial muscle regulated by host-guest interactions. Nat. Commun. 2012, 3, 1270; (b) Iwaso, K.; Takashima, Y.; Harada, A. Fast response dry-type artificial molecular muscles with [c2] daisy chains. Nat. Chem. 2016, 8 (6), 625-32.

(6) (a) Shinkai, S.; Nakaji, T.; Nishida, Y.; Ogawa, T.; Manabe, o. Photoresponsive Crown Ethers. 1. Cis-Trans Isomerism of Azobenzene as a Tool to Enforce Conformational Changes of Crown Ethers and Polymers. J. Am. Chem. Soc. 1980, 102 (18), 58605865; (b) Shinkai, S.; Nakaji, T.; Ogawa, T.; Shigematsu, K.; Manabe, O. Photoresponsive Crown Ethers. 2. Photocontrol of Ion Extraction and Ion Transport by a Bis(crown ether) with a Butterflylike Motion. J. Am. Chem. Soc. 1981, 103 (1), 111-115; (c) Yagai, S.;
Kitamura, A. Recent advances in photoresponsive supramolecular self-assemblies. Chem. Soc. Rev. 2008, 37 (8), 1520-9; (d) Tian, F.; Jiao, D.; Biedermann, F.; Scherman, O. A. Orthogonal switching of a single supramolecular complex. Nat. Commun. 2012, 3, 1207.

(7) (a) Klajn, R.; Wesson, P. J.; Bishop, K. J.; Grzybowski, B. A. Writing self-erasing images using metastable nanoparticle "inks". Angew. Chem., Int. Ed. 2009, 48 (38), 7035-9; (b) Raimondo, C.; Reinders, F.; Soydaner, U.; Mayor, M.; Samorì, P. Lightresponsive reversible solvation and precipitation of gold nanoparticles. Chem. Commun. 2010, 46 (7), 1147-9; (c) Manna, D.; Udayabhaskararao, T.; Zhao, H.; Klajn, R. Orthogonal LightInduced Self-Assembly of Nanoparticles using Differently Substituted Azobenzenes. Angew. Chem., Int. Ed. 2015, 54 (42), 12394-7.

(8) (a) Ferri, V.; Elbing, M.; Pace, G.; Dickey, M. D.; Zharnikov, M.; Samorì, P.; Mayor, M.; Rampi, M. A. Light-powered electrical switch based on cargo-lifting azobenzene monolayers. Angew. Chem., Int. Ed. 2008, 47 (18), 3407-9; (b) Mativetsky, J. M.; Pace, G.; Elbing, M.; Rampi, M. A.; Mayor, M.; Samorì, P. Azobenzenes as Light-Controlled Molecular Electronic Switches in Nanoscale Metal-Molecule-Metal Junctions. J. Am. Chem. Soc. 2008, 130 (29), 9192-9193.

(9) Crivillers, N.; Orgiu, E.; Reinders, F.; Mayor, M.; Samorì, P. Optical modulation of the charge injection in an organic fieldeffect transistor based on photochromic self-assembledmonolayer-functionalized electrodes. Adv. Mater. 2011, 23 (12), 1447-52.

(10) (a) Ichimura, K.; Suzuki, Y.; Seki, T.; Hosoki, A.; Aoki, K. Reversible Change in Alignment Mode of Nematic Liquid Crystals Regulated Photochemically by "Command Surfaces" Modified with an Azobenzene Monolayer. Langmuir 1988, 4 (5), 12141216; (b) Ikeda, T.; Tsutsumi, O. Optical Switching and Image Storage by Means of Azobenzene Liquid-Crystal Films. Science 1995, 268 (5219), 1873-5; (c) Yu, H.; Ikeda, T. Photocontrollable liquid-crystalline actuators. Adv. Mater. 2011, 23 (19), 2149-80; (d) Iamsaard, S.; Aßhoff, S. J.; Matt, B.; Kudernac, T.; Cornelissen, J. J.; Fletcher, S. P.; Katsonis, N. Conversion of light into macroscopic helical motion. Nat. Chem. 2014, 6 (3), 229-35; (e) Kumar, K.; Knie, C.; Bléger, D.; Peletier, M. A.; Friedrich, H.; Hecht, S.; Broer, D. J.; Debije, M. G.; Schenning, A. P. A chaotic self-oscillating sunlightdriven polymer actuator. Nat. Commun. 2016, 7, 11975; (f) Iamsaard, S.; Anger, E.; Aßhoff, S. J.; Depauw, A.; Fletcher, S. P.; Katsonis, N. Fluorinated Azobenzenes for Shape-Persistent Liquid Crystal Polymer Networks. Angew. Chem., Int. Ed. 2016, 55 (34), 9908-12; (g) Bisoyi, H. K.; Li, Q. Light-Driven Liquid Crystalline Materials: From Photo-Induced Phase Transitions and Property Modulations to Applications. Chem. Rev. 2016, 116 (24), 1508915166; (h) Gelebart, A. H.; Jan Mulder, D.; Varga, M.; Konya, A.; Vantomme, G.; Meijer, E. W.; Selinger, R. L. B.; Broer, D. J. Making Waves in a Photoactive Polymer Film. Nature 2017, 546 (7660), 632-636.

(11) (a) Baroncini, M.; d'Agostino, S.; Bergamini, G.; Ceroni, P.; Comotti, A.; Sozzani, P.; Bassanetti, I.; Grepioni, F.; Hernandez, T. M.; Silvi, S.; Venturi, M.; Credi, A. Photoinduced Reversible Switching of Porosity in Molecular Crystals Based on Star-Shaped Azobenzene Tetramers. Nat. Chem. 2015, 7 (8), 634-40; (b) Han, G. G. D.; Li, H.; Grossman, J. C. Optically-controlled long-term storage and release of thermal energy in phase-change materials. Nat. Commun. 2017, 8 (1), 1446.

(12) (a) Park, J.; Yuan, D.; Pham, K. T.; Li, J. R.; Yakovenko, A.; Zhou, H. C. Reversible alteration of $\mathrm{CO} 2$ adsorption upon photochemical or thermal treatment in a metal-organic framework. $J$. Am. Chem. Soc. 2012, 134 (1), 99-102; (b) Yanai, N.; Uemura, T.; Inoue, M.; Matsuda, R.; Fukushima, T.; Tsujimoto, M.; Isoda, S.; Kitagawa, S. Guest-to-host transmission of structural changes for stimuli-responsive adsorption property. J. Am. Chem. Soc. 2012, 134 (10), 4501-4; (c) Lyndon, R.; Konstas, K.; Ladewig, B. P.; Southon, P. D.; Kepert, P. C.; Hill, M. R. Dynamic Photo-Switching in Metal-Organic Frameworks as a Route to Low-Energy Carbon Dioxide Capture and Release. Angew. Chem., Int. Ed. 2013, 52 (13), 
3695-8; (d) Brown, J. W.; Henderson, B. L.; Kiesz, M. D.; Whalley, A. C.; Morris, W.; Grunder, S.; Deng, H.; Furukawa, H.; Zink, J. I.; Stoddart, J. F.; Yaghi, O. M. Photophysical pore control in an azobenzene-containing metal-organic framework. Chem. Sci. 2013, 4 (7), 2858; (e) Heinke, L.; Cakici, M.; Dommaschk, M.; Grosjean, S.; Herges, R.; Bräse, S.; Wöll, C. Photoswitching in Two-Component Surface-Mounted Metal-Organic Frameworks: Optically Triggered Release from a Molecular Container. ACS Nano 2014, 8 (2), 14637; (f) Castellanos, S.; Goulet-Hanssens, A.; Zhao, F.; Dikhtiarenko, A.; Pustovarenko, A.; Hecht, S.; Gascon, J.; Kapteijn, F.; Bléger, D. Structural Effects in Visible-Light-Responsive Metal-Organic Frameworks Incorporating ortho-Fluoroazobenzenes. Chem. Eur. J. 2016, 22 (2), 746-52; (g) Wang, Z.; Knebel, A.; Grosjean, S.; Wagner, D.; Bräse, S.; Wöll, C.; Caro, J.; Heinke, L. Tunable molecular separation by nanoporous membranes. Nat. Commun. 2016, 7 , 13872.

(13) (a) Cisnetti, F.; Ballardini, R.; Credi, A.; Gandolfi, M. T.; Masiero, S.; Negri, F.; Pieraccini, S.; Spada, G. P. Photochemical and Electronic Properties of Conjugated Bis(Azo) Compounds: an Experimental and Computational Study. Chem. Eur. J. 2004, 10 (8), 2011-21; (b) Bléger, D.; Dokic, J.; Peters, M. V.; Grubert, L.; Saalfrank, P.; Hecht, S. Electronic Decoupling Approach to Quantitative Photoswitching in Linear Multiazobenzene Architectures. J. Phys. Chem. B 2011, 115 (33), 9930-40; (c) Fihey, A.; Russo, R.; Cupellini, L.; Jacquemin, D.; Mennucci, B. Is Energy Transfer Limiting Multiphotochromism? Answers from Ab Initio Quantifications. Phys. Chem. Chem. Phys. 2017, 19 (3), 2044-2052.

(14) (a) De Feyter, S.; De Schryver, F. C. Two-dimensional supramolecular self-assembly probed by scanning tunneling microscopy. Chem. Soc. Rev. 2003, 32 (3), 139-150; (b) Clair, S.; Pons, S.; Seitsonen, A. P.; Brune, H.; Kern, K.; Barth, J. V. STM Study of Terephthalic Acid Self-Assembly on Au(111): HydrogenBonded Sheets on an Inhomogeneous Substrate. J. Phys. Chem. B 2004, 108 (38), 14585-14590; (c) Barth, J. V.; Costantini, G.; Kern, $\mathrm{K}$. Engineering atomic and molecular nanostructures at surfaces. Nature 2005, 437 (7059), 671-9; (d) Bartels, L. Tailoring molecular layers at metal surfaces. Nat. Chem. 2010, 2 (2), 87-95; (e) Cai, L.; Sun, Q.; Bao, M.; Ma, H.; Yuan, C.; Xu, W. Competition between Hydrogen Bonds and Coordination Bonds Steered by the Surface Molecular Coverage. ACS Nano 2017, 11 (4), 3727-3732.

(15) (a) Elemans, J. A.; Lei, S.; De Feyter, S. Molecular and supramolecular networks on surfaces: from two-dimensional crystal engineering to reactivity. Angew. Chem., Int. Ed. 2009, 48 (40), 7298-332; (b) Kudernac, T.; Lei, S.; Elemans, J. A.; De Feyter, S. Two-dimensional supramolecular self-assembly: nanoporous networks on surfaces. Chem. Soc. Rev. 2009, 38 (2), 402-21; (c) Ciesielski, A.; Palma, C. A.; Bonini, M.; Samorì, P. Towards supramolecular engineering of functional nanomaterials: preprogramming multi-component 2D self-assembly at solid-liquid interfaces. Adv. Mater. 2010, 22 (32), 3506-20.

(16) (a) El Malah, T.; Ciesielski, A.; Piot, L.; Troyanov, S. I.; Mueller, U.; Weidner, S.; Samorì, P.; Hecht, S. Conformationally pre-organized and $\mathrm{pH}$-responsive flat dendrons: synthesis and self-assembly at the liquid-solid interface. Nanoscale 2012, 4 (2), 467-72; (b) Yokoyama, S.; Hirose, T.; Matsuda, K. Phototriggered formation and disappearance of surface-confined self-assembly composed of photochromic 2-thienyl-type diarylethene: a cooperative model at the liquid/solid interface. Chem. Commun. 2014, 50 (45), 5964-6; (c) Frath, D.; Sakano, T.; Imaizumi, Y.; Yokoyama, S.; Hirose, T.; Matsuda, K. Diarylethene Self-Assembled Monolayers: Cocrystallization and Mixing-Induced Cooperativity Highlighted by Scanning Tunneling Microscopy at the Liquid/Solid Interface. Chem. Eur. J. 2015, 21 (32), 11350-8; (d) Bonacchi, S.; El Garah, M.; Ciesielski, A.; Herder, M.; Conti, S.; Cecchini, M.; Hecht, S.; Samorì, P. Surface-induced selection during in situ photoswitching at the solid/liquid interface. Angew. Chem., Int. Ed. 2015, 54 (16), 4865-4869; (e) Maeda, N.; Hirose, T.; Yokoyama, S.; Matsuda, K. Rational Design of Highly Photoresponsive SurfaceConfined Self-Assembly of Diarylethenes: Reversible Three-State
Photoswitching at the Liquid/Solid Interface. J. Phys. Chem. C 2016, 120 (17), 9317-9325; (f) Teyssandier, J.; De Feyter, S.; Mali, K. S. Host-guest chemistry in two-dimensional supramolecular networks. Chem. Commun. 2016, 52 (77), 11465-11487; (g) Iritani, K.; Tahara, K.; De Feyter, S.; Tobe, Y. Host-Guest Chemistry in Integrated Porous Space Formed by Molecular Self-Assembly at Liquid-Solid Interfaces. Langmuir 2017, 33 (19), 4601-4618.

(17) (a) Alemani, M.; Peters, M. V.; Hecht, S.; Rieder, K. H.; Moresco, F.; Grill, L. Electric Field-Induced Isomerization of Azobenzene by STM. J. Am. Chem. Soc. 2006, 128 (45), 14446-7; (b) Pace, G.; Ferri, V.; Grave, C.; Elbing, M.; von Hänisch, C.; Zharnikov, M.; Mayor, M.; Rampi, M. A.; Samorì, P. Cooperative light-induced molecular movements of highly ordered azobenzene selfassembled monolayers. Proc. Natl. Acad. Sci. U. S. A. 2007, 104 (24), 9937-42; (c) Dri, C.; Peters, M. V.; Schwarz, J.; Hecht, S.; Grill, L. Spatial periodicity in molecular switching. Nat. Nanotechnol. 2008, 3 (11), 649-53; (d) Scheil, K.; Gopakumar, T. G.; Bahrenburg, J.; Temps, F.; Maurer, R. J.; Reuter, K.; Berndt, R. Switching of an Azobenzene-Tripod Molecule on Ag(111). J. Phys. Chem. Lett. 2016, 7 (11), 2080-4.

(18) (a) Feng, C. L.; Zhang, Y.; Jin, J.; Song, Y.; Xie, L.; Qu, G.; Jiang, L.; Zhu, D. Completely interfacial photoisomerization of 4hydroxy-30-trifluoromethyl-azobenzene studied by STM on HOPG. Surf. Sci. 2002, 513, 111-118; (b) Bléger, D.; Ciesielski, A.; Samorì, P.; Hecht, S. Photoswitching vertically oriented azobenzene self-assembled monolayers at the solid-liquid interface. Chem. Eur. J. 2010, 16 (48), 14256-60.

(19) Tahara, K.; Inukai, K.; Adisoejoso, J.; Yamaga, H.; Balandina, T.; Blunt, M. O.; De Feyter, S.; Tobe, Y. Tailoring surfaceconfined nanopores with photoresponsive groups. Angew. Chem., Int. Ed. 2013, 52 (32), 8373-6.

(20) (a) Shen, Y. T.; Guan, L.; Zhu, X. Y.; Zeng, Q. D.; Wang, C. Submolecular Observation of Photosensitive Macrocycles and Their Isomerization Effects on Host-Guest Network. J. Am. Chem. Soc. 2009, 131 (17), 6174-6180; (b) Shen, Y. T.; Deng, K.; Zhang, X. M.; Feng, W.; Zeng, Q. D.; Wang, C.; Gong, J. R. Switchable ternary nanoporous supramolecular network on photo-regulation. Nano Lett. 2011, 11 (8), 3245-50; (c) Shen, Y.-t.; Deng, K.; Zhang, X.-m.; Lei, D.; Xia, Y.; Zeng, Q.-d.; Wang, C. Selective and Competitive Adsorptions of Guest Molecules in Phase-Separated Networks. J. Phys. Chem. C 2011, 115 (40), 19696-19701.

(21) (a) Côté, A. P.; El-Kaderi, H. M.; Furukawa, H.; Hunt, J. R.; Yaghi, O. M. Reticular Synthesis of Microporous and Mesoporous 2D Covalent Organic Frameworks. J. Am. Chem. Soc. 2007, 129 (43), 12914-5; (b) Ghosh, K.; Hu, J.; White, H. S.; Stang, P. J. Construction of Multifunctional Cuboctahedra via CoordinationDriven Self-Assembly. J. Am. Chem. Soc. 2009, 131 (19), 6695-7; (c) Furukawa, H.; Ko, N.; Go, Y. B.; Aratani, N.; Choi, S. B.; Choi, E.; Yazaydin, A. O.; Snurr, R. Q.; O'Keeffe, M.; Kim, J.; Yaghi, O. M. Ultrahigh Porosity in Metal-Organic Frameworks. Science 2010, 329 (5990), 424-8; (d) Vijayaraghavan, S.; Ecija, D.; Auwarter, W.; Joshi, S.; Seufert, K.; Drach, M.; Nieckarz, D.; Szabelski, P.; Aurisicchio, C.; Bonifazi, D.; Barth, J. V. Supramolecular Assembly of Interfacial Nanoporous Networks with Simultaneous Expression of Metal-Organic and Organic-Bonding Motifs. Chem. Eur. J. 2013, 19 (42), 14143-50; (e) Ciesielski, A.; Szabelski, P. J.; Rzysko, W.; Cadeddu, A.; Cook, T. R.; Stang, P. J.; Samorì, P. Concentrationdependent supramolecular engineering of hydrogen-bonded nanostructures at surfaces: predicting self-assembly in 2D. J. Am. Chem. Soc. 2013, 135 (18), 6942-50.

(22) (a) Griessl, S.; Lackinger, M.; Edelwirth, M.; Hietschold, M.; Heckl, W. M. Self-Assembled Two-Dimensional Molecular Host-Guest Architectures From Trimesic Acid. Single Mol. 2002, 3 (1), 25-31; (b) Lackinger, M.; Griessl, S.; Markert, T.; Jamitzky, F.; Heckl, W. M. Self-Assembly of Benzene-Dicarboxylic Acid Isomers at the Liquid Solid Interface: Steric Aspects of Hydrogen Bonding. J. Phys. Chem. B 2004, 108 (36), 13652-13655; (c) Lackinger, M.; Griessl, S.; Heckl, W. A.; Hietschold, M.; Flynn, G. W. Self-Assembly of Trimesic Acid at the Liquid-Solid Interfaces - a Study of Sol- 
vent-Induced Polymorphism. Langmuir 2005, 21 (11), 49844988; (d) Ruben, M.; Payer, D.; Landa, A.; Comisso, A.; Gattinoni, C.; Lin, N.; Collin, J. P.; Sauvage, J. P.; De Vita, A.; Kern, K. 2D Supramolecular Assemblies of Benzene-1,3,5-triyl-tribenzoic Acid: Temperature-Induced Phase Transformations and Hierarchical Organization with Macrocyclic Molecules. J. Am. Chem. Soc. 2006, 128 (49), 15644-51; (e) Zhou, H.; Dang, H.; Yi, J. H.; Nanci, A.; Rochefort, A.; Wuest, J. D. Frustrated 2D Molecular Crystallization. J. Am. Chem. Soc. 2007, 129 (45), 13774-5; (f) Ye, Y. C.; Sun, W.; Wang, Y. F.; Shao, X.; Xu, X. G.; Cheng, F.; Li, J. L.; Wu, K. A Unified Model: Self-Assembly of Trimesic Acid on Gold. J. Phys. Chem. C 2007, 111 (28), 10138-10141; (g) Blunt, M.; Lin, X.; GimenezLopez, M. d. C.; Schröder, M.; Champness, N. R.; Beton, P. H. Directing two-dimensional molecular crystallization using guest templates. Chem. Commun. 2008, (20), 2304-6; (h) Lackinger, M.; Heckl, W. M. Carboxylic acids: versatile building blocks and mediators for two-dimensional supramolecular self-assembly. Langmuir 2009, 25 (19), 11307-21; (i) Ha, N. T. N.; Gopakumar, T. G.; Gutzler, R.; Lackinger, M.; Tang, H.; Hietschold, M. Influence of Solvophobic Effects on Self-Assembly of Trimesic Acid at the Liquid-Solid Interface. J. Phys. Chem. C 2010, 114 (8), 3531-3536; (j) Eder, G.; Kloft, S.; Martsinovich, N.; Mahata, K.; Schmittel, M.; Heckl, W. M.; Lackinger, M. Incorporation dynamics of molecular guests into two-dimensional supramolecular host networks at the liquid-solid interface. Langmuir 2011, 27 (22), 13563-71.

(23) Dienstmaier, J. F.; Mahata, K.; Walch, H.; Heckl, W. M.; Schmittel, M.; Lackinger, M. On the scalability of supramolecular networks - high packing density vs optimized hydrogen bonds in tricarboxylic acid monolayers. Langmuir 2010, 26 (13), 1070816. 